\title{
Analysis of Risk Factors Associated with Reduced Trough Concentrations of Vancomycin in Relation to Renal Function in a Tertiary Hospital in Japan
}

\author{
Shota Kashiwagura' \\ Yasuhiro Kamioka' \\ Masafumi Seki (D) ${ }^{2}$ \\ Satoshi Koshika' \\ Kouji Okada (D) ${ }^{1,3}$
}

'Department of Pharmacy, Tohoku Medical and Pharmaceutical University Hospital, Sendai City, Miyagi, Japan;

${ }^{2}$ Division of Infectious Diseases and Infection Control, Faculty of Medicine, Tohoku Medical and Pharmaceutical University, Sendai City, Miyagi, Japan; ${ }^{3}$ Division of Clinical Pharmaceutics and Pharmacy Practice, Faculty of Pharmaceutics, Tohoku Medical and Pharmaceutical University, Sendai City, Miyagi, Japan
Correspondence: Masafumi Seki Division of Infectious Diseases and Infection Control, Faculty of Medicine, Tohoku Medical and Pharmaceutical University, I-I5-I Fukumuro, Miyagino-ku, Sendai City, Miyagi, 983-8536, Japan

Tel +8I-22-983-I 221

Fax +8I-22-290-8959

Email m-seki@tohoku-mpu.ac.jp;

seki@hosp.tohoku-mpu.ac.jp
Background: Low trough concentrations of vancomycin (VCM) are common in patients receiving the drug, because patients are often administered relatively low doses of VCM due to its high potential for renal toxicity. However, the clinical risk factors associated with low VCM trough concentration in relation to renal function are unclear

Methods: Patients at our hospital who received VCM intravenously from January 2018 to December 2020 were analyzed. The patients were divided into two groups based on their renal function: normal and lower renal function, such as estimated glomerular filtration rate (eGFR) $\geqq 60$ and $<60 \mathrm{~mL} / \mathrm{min} / 1.73 \mathrm{~m}^{2}$, respectively. In each renal function group, patients' background characteristics, laboratory data and treatments were compared between lower VCM concentration $(<10 \mathrm{mg} / \mathrm{L})$ and appropriate VCM concentration $(10-20 \mathrm{mg} / \mathrm{L})$ subgroups.

Results: Among 101 patients with normal renal function, 47 and 54 patients, respectively, showed lower and appropriate VCM trough concentrations. Elderly age, short stature, and higher C-reactive protein (CRP) level were significantly more common in the lower VCM concentration group compared with appropriate VCM concentration group. Among the 45 patients with renal dysfunction, 20 and 25 patients, respectively, showed lower and appropriate VCM trough concentrations. CRP levels were significantly higher in lower VCM concentration than appropriate VCM concentration subgroups. Multivariate analysis showed that insufficient total VCM doses and higher CRP might have affected the lower VCM trough concentration in patients with normal renal function.

Conclusion: The results of this study suggest that higher CRP might be one of the risk factors associated with lower VCM concentration in both normal and low renal function patients. Severely ill and emergency patients might receive a lower VCM dose due to underestimation of the acceptable VCM dose.

Keywords: therapeutic drug monitoring, vancomycin, estimated glomerular filtration rate, C-reactive protein

\section{Introduction}

Methicillin-resistant $S$. aureus (MRSA) is currently a common cause of hospital-acquired infections, and a multinational surveillance study suggested a high prevalence of MRSA in many countries. ${ }^{1,2}$ In Japan, MRSA-related diseases, including bacteremia, skin and soft tissue infections and pneumonia are serious issues, occurring at a high frequency and with a high risk of mortality, and exhibit resistance to several antibiotics. ${ }^{3}$

Vancomycin (VCM) is a representative anti-MRSA agent that is used worldwide. However, due to its potential for causing renal toxicity, its strict use, including with therapeutic drug monitoring (TDM), is strongly recommended to prevent 
kidney dysfunction and high blood concentrations of the drug, as with other anti-MRSA agents, such as teicoplanin. ${ }^{4,5}$ Therefore, to strike a balance between clinical efficacy and safety, establishing the initial dosage and measurement of trough VCM values on day 3 of therapy are mandatory during TDM. ${ }^{5,6}$

The ratio of the area under the curve over 24 hours to the minimum inhibitory concentration (AUC/MIC) of VCM of $\geq 400$ is the primary pharmacokinetic/pharmacodynamic (PK/PD) indicator of VCM activity, and promoting serum trough concentrations of 15 to $20 \mathrm{mg} / \mathrm{L}$ as a surrogate marker for the optimal vancomycin $\mathrm{AUC} /$ MIC if the MIC of MRSA was $\leq 1 \mathrm{mg} / \mathrm{L}$ although much more recommended use of AUC/MIC of $\mathrm{VCM}$ of $\geq 400$ than trough concentration recently. ${ }^{7}$ The AUC/MIC ratio of 400 or more is associated with improved clinical response and microbiologic eradication in adult patients with MRSA lower respiratory tract infection. ${ }^{8}$ In children, the recommended dose of VCM for serious or invasive diseases ranged from $15 \mathrm{mg} / \mathrm{kg} /$ dose every $6 \mathrm{~h}(60 \mathrm{mg} / \mathrm{kg} /$ day) up to $20 \mathrm{mg} / \mathrm{kg} /$ dose every $6 \mathrm{~h}$ (80 $\mathrm{mg} / \mathrm{kg} /$ day $)$ for MRSA with MIC of $1 \mathrm{mg} / \mathrm{mL}$ or less to $\mathrm{VCM},{ }^{9}$ and correlation between VCM trough and AUC/MIC of VCM values in children has been observed although the values of trough that correlate with the target AUC/MIC of VCM of $\geq 400$ in children are lower than the values observed and targeted in adults. ${ }^{10}$

In order to achieve an initial target trough VCM value of 15 to $20 \mu \mathrm{g} / \mathrm{mL}$ as the dose setting after VCM administration, although a trough value of 10 to $15 \mu \mathrm{g} / \mathrm{mL}$ is also acceptable, the 2016 Japanese guidelines published by the Japanese Society of Chemotherapy and the Japanese Society of Therapeutic Drug Monitoring for TDM of VCM (GL2016) described specific dosages according to renal function. ${ }^{5,6}$ Since September 2016, our hospital has been determining the therapeutic dosage of VCM based on the GL2016 and by measurement of its trough values. However, low trough concentrations of VCM were frequently observed in patients with deterioration of renal function in whom relatively lose doses of VCM might have been administered. ${ }^{11}$

Additionally, the clinical risk factors associated with low VCM trough concentrations in patients stratified according to renal function are unclear. In this study, we analyzed patients who received VCM intravenously in order to determine the risk factors of lower VCM trough concentration and insufficient clinical effect by comparing patients with normal renal function, with an eGFR of $\geqq 60 \mathrm{~mL} / \mathrm{min} / 1.73 \mathrm{~m}^{2}$, with patients with renal dysfunction, with an eGFR of $<60 \mathrm{~mL} / \mathrm{min} / 1.73 \mathrm{~m}^{2}$, and found C-reactive protein (CRP) levels were significantly higher in lower VCM concentration than appropriate VCM concentration subgroups.

\section{Methods}

\section{Study Subjects}

A total of 279 patients who received VCM intravenously at our institution to treat the MRSA infectious diseases, including bacteremia, skin and soft tissue infections, surgical site infection, endocarditis, and pneumonia between January 2018 and December 2020, were retrospectively investigated (Figure 1). Inclusion criteria were as follows: older than 18 years, received vancomycin in the setting of suspected MRSA infection, and administered VCM intravenously more than 7 days, respectively. Among them, one minor patient, 58 patients who received hemodialysis, 61 patients in whom the trough value of VCM was not measured, and 13 patients who had a trough VCM value of more than $20 \mu \mathrm{g} / \mathrm{mL}$ were excluded due to their being inappropriate subjects for this study because high trough value of VCM reflect the renal functions and we could not distinguish the chronic kidney disease (CKD) as the basic complications from the side effects of high dose VCM.

The remaining 146 patients were divided into two groups based on their renal function: the normal renal function group: eGFR $\geqq 60 \mathrm{~mL} / \mathrm{min} / 1.73 \mathrm{~m}^{2} \quad(\mathrm{n}=101)$, and the renal dysfunction group: eGFR $<60 \mathrm{~mL} / \mathrm{min} /$ $1.73 \mathrm{~m}^{2}(\mathrm{n}=45)$, respectively (Figure 1$)$.

The 2012 Clinical Practice Guidebook for Diagnosis and Treatment of CKD guidelines were used for classifying the severity of renal dysfunction. ${ }^{12}$

Furthermore, in each group, factors such as patients' background characteristics, laboratory data and treatments were compared between the lower VCM concentration subgroup $(<10 \mathrm{mg} / \mathrm{L})$, and the appropriate VCM concentration subgroup (between 10 and $20 \mathrm{mg} / \mathrm{L}$ ), respectively, in the serum at the Day 3 after VCM administration were started.

\section{Blood Sampling}

Blood samples of $\sim 2.5 \mathrm{~mL}$ were obtained 72 hours after the initiation of VCM infusion. All blood samples were allowed to clot and then centrifuged at $2000 \mathrm{rpm}$. The serum obtained was stored at $-80^{\circ} \mathrm{C}$ until analyzed. 


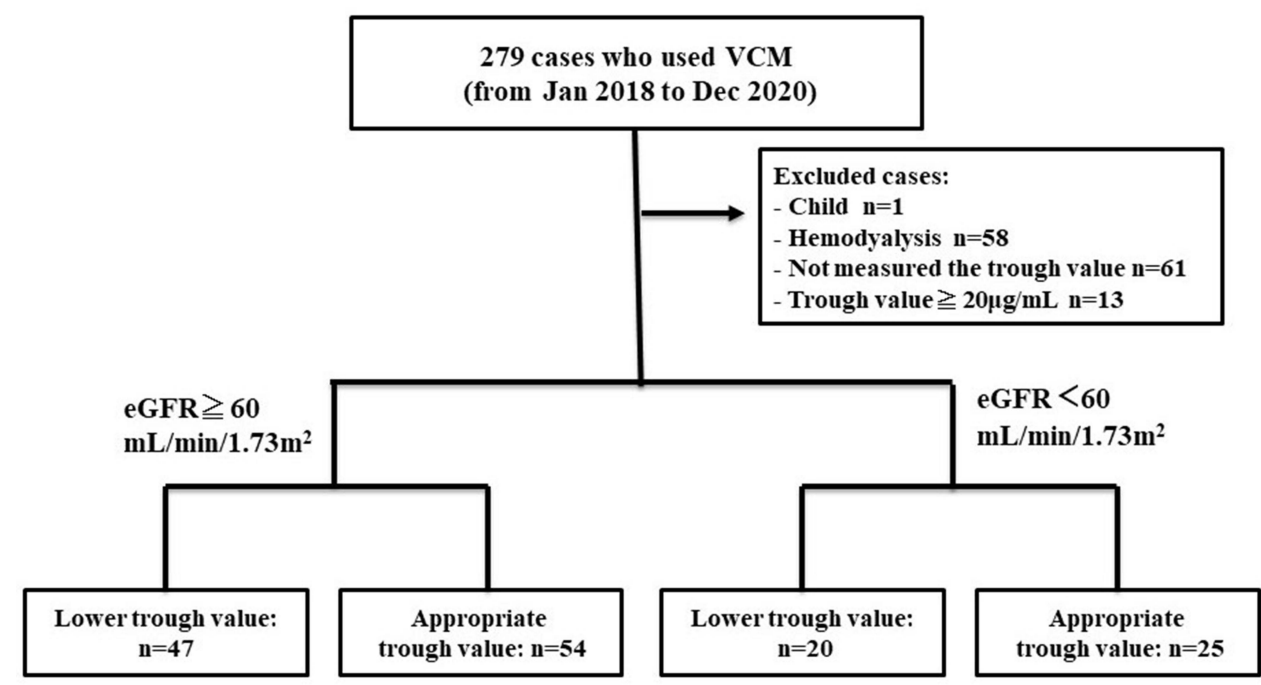

Total: $\mathbf{n}=\mathbf{1 0 1}$

Total: $\mathbf{n}=\mathbf{4 5}$

Figure I Flowchart of the study population.

\section{VCM Assays}

Concentrations of VCM in serum were determined by fluorescence polarization immunoassay (AxSYM; Abbott Laboratories, Abbott Park, IL, USA). The assay limit of detection of VCM was $2 \mu \mathrm{g} / \mathrm{mL}$. Furthermore, we did not use trough concentration/daily dose (C0/D) unfortunately because C0/D is not available in Japan, and we have analyzed separately the trough concentration and total daily dose.

\section{PK/PD Analysis}

VCM PK analyses were conducted using two approaches: the noncompartmental modeling (modelindependent methods) and the compartmental modeling using PhoenixR WinNonlinR Version 6.3 (CertaraTM, St. Louis, MO, USA) to determine the PK parameters of interest in each individual patient. The probability of achieving the PD target of AUC24/MIC $\geq 400$ in patients treated with VCM was assessed using AUC24/MIC model and parameters estimated from the PK analysis using by the VCM analysis computer software (VCM-soft). ${ }^{11}$

\section{Ethical Considerations}

This study was conducted in accordance with the Declaration of Helsinki and approved by the Committee for Clinical Scientific Research of Tohoku Medical and Pharmaceutical University Hospital (approval numbers ID2017-2-030 and -033) and all patients provided written informed consent for use of their blood samples, although measurement and estimation of VCM concentrations in blood are an essential part of our routine hospital pharmacological procedures.

\section{Statistical Analysis}

Normally distributed clinical and demographic data were subjected to analysis of variance, with Fisher's exact test for multiple comparisons; non-normally distributed data were analyzed by non-parametric statistics, such as the Mann-Whitney U-test. When necessary, the results were further corrected using the Bonferroni method. The 95\% confidence intervals (CIs) of risk factors affecting lower trough values of VCM were estimated using univariate and multivariate logistic regression analysis. Multivariate logistic analysis was performed using logistic regression models. Variables achieving a probable $p$ value of $<0.2$ in univariate logistic analysis were included in multivariate analysis to determine the factors associated with a lower VCM trough value. Predictive values are presented as odds ratios (ORs) with their respective 95\% CIs.

All the other data are presented as the mean \pm SD. A p-value of less than 0.05 denoted a statistically significant difference. All analyses were carried out using Stat View software (Abacus Concepts, Cary, NC, USA) and SPSS Statistics version 25 (IBM: International Business Machines Corporation, Armonk NY, USA). 


\section{Results}

\section{Background Factors, Laboratory Data and} Treatments in Patients with Normal Renal Function

Among the 101 patients with normal renal function, 47 and 54 patients, respectively, had lower and appropriate VCM concentrations (Table 1).

Elderly patients, those of a short stature, and with hematological malignancy exhibited lower VCM concentrations, although male/female ratio, body weight, body surface area, body mass index (BMI) and temperature were similar between low and normal VCM concentration subgroups among patients with normal renal function.

In terms of laboratory data, C-reactive protein (CRP) levels were significantly higher in the low VCM concentration subgroup than the normal VCM concentration group. The biomarkers of renal function, white blood cell counts and albumin concentrations were not significantly different between the two groups.

The total dose of VCM was significantly lower in the lower VCM concentration subgroup than the normal VCM concentration subgroup. Both estimated and actual trough VCM concentrations were lower in the lower VCM concentration

Table I Background Characteristics of Patients with Normal Kidney Function, ie, with an eGFR of $\geqq 60 \mathrm{~mL} / \mathrm{min} / 1.73 \mathrm{~m}{ }^{2}$

\begin{tabular}{|c|c|c|c|}
\hline & \multicolumn{3}{|l|}{ eGFR $\geqq 60 \mathrm{~mL} / \mathrm{min} / 1.73 \mathrm{~m}^{2}$} \\
\hline & Lower Trough Group $(n=47)$ & Appropriate Trough Group $(n=54)$ & $\mathbf{P}$ value \\
\hline \multicolumn{4}{|l|}{ Backgrounds } \\
\hline Gender (Male) & 28 & 41 & $0.09^{\mathrm{a}}$ \\
\hline Age (years, Median) & $78.0(63-8 I)$ & $70.0(63-77)$ & $0.047^{b}$ \\
\hline Height (cm) & $158.6 \pm 10.4$ & $163.3 \pm 9.4$ & $0.02^{\mathrm{c}}$ \\
\hline Weight (kg) & $53.5 \pm 12.7$ & $55.9 \pm 11.9$ & $0.33^{c}$ \\
\hline Body surface area $\left(\mathrm{m}^{2}\right)$ & $1.53 \pm 0.21$ & $1.59 \pm 0.18$ & $0.11^{\mathrm{c}}$ \\
\hline BMI & $20.6(19.0-22.8)$ & $20.5(|8|-.24 . \mid)$ & $0.88^{\mathrm{b}}$ \\
\hline Solid tumor & 13 & 22 & $0.21^{\mathrm{a}}$ \\
\hline Hematological malignancy & 8 & 2 & $0.04^{\mathrm{a}}$ \\
\hline Heart failure & 8 & 15 & $0.24^{\mathrm{a}}$ \\
\hline Temperature $\left({ }^{\circ} \mathrm{C}\right)$ & $38.3(37.2-39.0)$ & $37.8(36.9-38.6)$ & $0.19^{\mathrm{b}}$ \\
\hline \multicolumn{4}{|l|}{ Laboratory data } \\
\hline BUN (mg/dL) & $14.0(11.0-18.5)$ & $17.0(13.3-19.0)$ & $0.18^{\mathrm{b}}$ \\
\hline Scr $(m g / d L)$ & $0.63 \pm 0.15$ & $0.69 \pm 0.18$ & $0.07^{c}$ \\
\hline eGFR $\left(\mathrm{mL} / \mathrm{min} / 1.73 \mathrm{~m}^{2}\right)$ & $82.0(73.0-95.0)$ & $76.9(64.6-85.2)$ & $0.42^{\mathrm{b}}$ \\
\hline eGFR (mL/min) & $69.6(62.7-88.6)$ & $74.4(64.6-85.7)$ & $0.44^{\mathrm{b}}$ \\
\hline CLcr (mL/min) & $69.9(55.2-94.8)$ & $76.5(60.8-100.5)$ & $0.30^{\mathrm{b}}$ \\
\hline WBC $(/ \mu \mathrm{L})$ & $9700(5400-13,550)$ & $7850(5450-10,625)$ & $0.43^{\mathrm{b}}$ \\
\hline CRP (mg/dL) & $9.88(5.45-15.49)$ & $6.25(2.77-10.59)$ & $0.02^{\mathrm{b}}$ \\
\hline Alb (g/dL) & $2.69 \pm 0.58$ & $2.56 \pm 0.60$ & $0.27^{c)}$ \\
\hline $\mathrm{BNP}(\mathrm{pg} / \mathrm{mL})$ & $61.6(21.7-197.2)$ & I34.I (52.9-367.6) & $0.07^{\mathrm{b}}$ \\
\hline \multicolumn{4}{|l|}{ Treatments } \\
\hline Loading use & 18 & 13 & $0.14^{\mathrm{a}}$ \\
\hline VCM use until first measure (times) & $5(4.0-6.5)$ & $5(4.3-6.0)$ & $0.54^{\mathrm{b}}$ \\
\hline Estimated trough value $(\mu \mathrm{g} / \mathrm{mL})$ & $\mathrm{II} . \mathrm{I} \pm 4.4$ & $13.4 \pm 3.3$ & $<0.01^{\mathrm{c}}$ \\
\hline Practical trough value $(\mu \mathrm{g} / \mathrm{mL})$ & $7.2 \pm 2.1$ & $12.9 \pm 2.3$ & $<0.01^{\mathrm{c}}$ \\
\hline Transfusion (L) & $3.5(2.4-5.1)$ & $2.9(1.1-4.1)$ & $0.056^{\mathrm{b}}$ \\
\hline Diuretic use & 10 & 18 & $0.19^{\mathrm{a}}$ \\
\hline Catecholamine use & 2 & 3 & $\mathrm{I}^{\mathrm{a}}$ \\
\hline Operation within 48 hours & 4 & 4 & $I^{\mathrm{a}}$ \\
\hline Within 14 days & 9 & 8 & $0.60^{\mathrm{a}}$ \\
\hline Within 30 days & 11 & 11 & $0.8 \mathrm{I}^{\mathrm{a}}$ \\
\hline
\end{tabular}

Notes: a Fisher's exact test, ' Mann-Whitney U-test, 'Student's t-test: mean \pm SD.

Abbreviations: BMI, body mass index; BUN, blood urea nitrogen; Scr, serum creatinine; eGFR, estimated glomerular filtration rate; CLcr, creatinine clearance; WBC, white blood cell; CRP, C-reactive protein; Alb, albumin; BNP, brain natriuretic peptide; VCM, vancomycin, respectively. 
subgroup than the normal VCM concentration subgroup. Loading dose of VCM, transfusions, diuretic usage, catecholamine usage, and time interval between start of the VCM administration and surgery were similar between the low and appropriate VCM trough subgroups in patients with normal renal function.

\section{Background Factors, Laboratory Data and Treatments in Patients with Renal Dysfunction}

Among the 45 renal dysfunction group patients, 20 and 25 patients, respectively, had lower and appropriate VCM concentrations (Table 2).
The background characteristics were similar between patients with lower and normal VCM trough concentrations, although in terms of laboratory data, CRP levels were significantly higher and brain natriuretic peptide (BNP) levels were significantly lower in the lower VCM concentration subgroup compared with the appropriate VCM concentration subgroup.

In terms of treatments, the estimated trough value and actual trough value were lower in the lower VCM concentration subgroup than the normal VCM concentration subgroup, although the total dose of VCM was similar between the two groups. Loading dose of VCM, transfusion, diuretic usage, catecholamine usage, and time

Table 2 Background Characteristics of Patients with Decreased Renal Function, ie, an eGFR of $<60 \mathrm{~mL} / \mathrm{min} / 1.73 \mathrm{~m}{ }^{2}$

\begin{tabular}{|c|c|c|c|}
\hline & \multicolumn{3}{|l|}{ eGFR $<60 \mathrm{~mL} / \mathrm{min} / 1.73 \mathrm{~m}^{2}$} \\
\hline & Lower Trough Group $(n=20)$ & Appropriate Trough Group $(n=25)$ & $P$ value \\
\hline \multicolumn{4}{|l|}{ Backgrounds } \\
\hline Gender (Female) & 14 & 14 & $0.37^{\mathrm{a}}$ \\
\hline Age (years, Median) & $75.3 \pm 7.9$ & $75.1 \pm 10.3$ & $0.95^{\mathrm{c}}$ \\
\hline Height $(\mathrm{cm})$ & $158.7 \pm 9.2$ & $157.1 \pm 8.6$ & $0.54^{\mathrm{c}}$ \\
\hline Weight (kg) & $59.6 \pm 13.8$ & $57.4 \pm 14.8$ & $0.6 \mathrm{I}^{\mathrm{c}}$ \\
\hline Body surface area $\left(\mathrm{m}^{2}\right)$ & $1.60 \pm 0.22$ & $1.56 \pm 0.20$ & $0.5 \mathrm{I}^{\mathrm{c}}$ \\
\hline BMI & $23.4 \pm 3.8$ & $23.2 \pm 5.5$ & $0.87^{c}$ \\
\hline Solid Tumor & 7 & 5 & $0.32^{\mathrm{a}}$ \\
\hline Hematological malignancy & I & 4 & $0.36^{\mathrm{a}}$ \\
\hline Heart failure & 5 & 13 & $0.08^{\mathrm{a}}$ \\
\hline Temperature $\left({ }^{\circ} \mathrm{C}\right)$ & $37.7(37.2-39.3)$ & $37.6(37.2-38.2)$ & $0.4 I^{b}$ \\
\hline \multicolumn{4}{|l|}{ Laboratory data } \\
\hline BUN (mg/dL) & $22.5(16.8-26.8)$ & $25.0(21.0-55.0)$ & $0.16^{\mathrm{b}}$ \\
\hline Scr $(m g / d L)$ & $1.15(0.97-1.28)$ & $1.19(1.03-1.59)$ & $0.34^{\mathrm{b}}$ \\
\hline eGFR $\left(\mathrm{mL} / \mathrm{min} / 1.73 \mathrm{~m}^{2}\right)$ & $46.5(39.3-50.3)$ & $45.0(30.0-50.0)$ & $0.21^{\mathrm{b}}$ \\
\hline eGFR (mL/min) & $41.8 \pm 9.6$ & $36.6 \pm 12.0$ & $0.13^{c}$ \\
\hline CLcr (mL/min) & $44.8(38.1-48.8)$ & $43.1(25.4-46.4)$ & $0.31^{\mathrm{b}}$ \\
\hline WBC $(/ \mu \mathrm{L})$ & $10,150(6325-11,525)$ & $11,300(5900-16,300)$ & $0.88^{\mathrm{b}}$ \\
\hline $\mathrm{CRP}(\mathrm{mg} / \mathrm{dL})$ & II.5 (5.I-22.3) & $7.3(2.2-14.0)$ & $0.01^{\mathrm{b}}$ \\
\hline Alb (g/dL) & $2.61 \pm 0.63$ & $2.62 \pm 0.60$ & $0.97^{c}$ \\
\hline BNP $(\mathrm{pg} / \mathrm{mL})$ & $76.7(38.3-136.2)$ & $198.2(96.5-492.1)$ & $0.02^{\mathrm{b}}$ \\
\hline \multicolumn{4}{|l|}{ Treatments } \\
\hline Loading use & 5 & 13 & $0.07^{\mathrm{a}}$ \\
\hline VCM use until first measure (times) & $4(4.0-4.3)$ & $4(4.0-5.0)$ & $0.46^{\mathrm{b}}$ \\
\hline Estimated trough value $(\mu \mathrm{g} / \mathrm{mL})$ & $12.4(11.4-13.3)$ & $15.1(13.2-17.1)$ & $<0.01^{b}$ \\
\hline Practical trough value $(\mu \mathrm{g} / \mathrm{mL})$ & $6.34 \pm 2.0$ & $13.3 \pm 2.4$ & $<0.01^{\mathrm{c}}$ \\
\hline Transfusion (L) & $3.36 \pm 2.15$ & $3.00 \pm 1.80$ & $0.49^{c}$ \\
\hline Diuretic use & 7 & 12 & $0.55^{\mathrm{a}}$ \\
\hline Catecholamine use & I & 0 & $0.44^{\mathrm{a}}$ \\
\hline Operation within 48 hours & 2 & 1 & $0.58^{\mathrm{a}}$ \\
\hline Within 14 days & 7 & 6 & $0.52^{\mathrm{a}}$ \\
\hline Within 30 days & 8 & 8 & $0.76^{\mathrm{a}}$ \\
\hline
\end{tabular}

Notes: ${ }^{a}$ Fisher's exact test, ${ }^{b}$ Mann-Whitney U-test, 'Student's $t$-test: mean \pm SD.

Abbreviations: BMI, body mass index; BUN, blood urea nitrogen; Scr, serum creatinine; eGFR, estimated glomerular filtration rate; CLcr, creatinine clearance; WBC, white blood cell; CRP, C-reactive protein; Alb, albumin; BNP, brain natriuretic peptide; VCM, vancomycin, respectively. 
interval between start of the VCM administration were similar in the two groups, as in the 101 patients with normal renal function.

\section{Multivariate Analysis of Factors Affecting the Lower Trough Value of Vancomycin in Patients with Normal Renal Function}

Multivariate analysis of factors showed that an insufficient total dose of VCM might have affected the lower VCM trough concentrations in patients with normal renal function (Table 3). In addition, higher CRP was also shown to be one of the significant factors related to lower VCM trough. Age, eGFR $\left(\mathrm{mL} / \mathrm{min} / 1.73 \mathrm{~m}^{2}\right)$ and diuretic use were considered to be risk factors for lower VCM trough concentrations because variables achieving a probable $p$ value $<0.2$ in univariate logistic analysis; however, the results of multivariate analysis were not statistically significant.

Unfortunately, we could not perform multivariate analysis of factors affecting a lower trough value of VCM in patients with renal dysfunction because of an insufficient number of such patients (data not shown).

\section{Discussion}

VCM is a relatively hydrophilic antibiotic, and the leakage of the fluid from the vessels may result in the larger volume of VCM distribution, as well as decrease its plasma drug concentration in critically ill patients. ${ }^{13}$ The primary response in critically ill patients caused by the release of intrinsic mediators by the host as a reaction to bacterial toxins leads to the increase in capillary permeability, edema formation, vasodilatation, and hypotension. These alterations in pathophysiological conditions may result in PK changes in several antibiotics, including VCM.

In this study, the results showed that in patients with normal renal function, ie an eGFR of $\geqq 60 \mathrm{~mL} / \mathrm{min} / 1.73 \mathrm{~m}^{2}$, elderly age, short stature, and higher CRP levels were significantly associated with lower VCM trough concentrations. In patients with renal dysfunction as well, CRP levels were significantly higher in the lower VCM concentration subgroup than the appropriate VCM concentration subgroup. For the first time, it was reported the relation between CRP and VCM trough concentration was significant, and the multivariate analysis data suggested that higher CRP levels, such as in patients with severe inflammation, including a septic status, might be one of the most important factors, among others, associated with lower trough concentrations of VCM.

Usually, increased permeable VCM in the tissue and augmented renal clearance (ARC), characterized by increased creatinine clearance and elimination of renal eliminated medications, are found in critically ill patients, such as those with severe neurological injury, trauma, burns and sepsis. ${ }^{14,15}$ Septic conditions were more critical in short status and also appeared in hematological diseases ${ }^{16}$ as we found lower VCM trough in these patients in this study. Several mechanisms, including endogenous responses to increased metabolism and solute production, alterations in neurohormonal balance, and therapeutic maneuvers, such as fluid resuscitation, are considered to contribute to augmented renal clearance (ARC) and might be associated with suboptimal exposure to critical medications, including $\beta$-lactams and VCM, increasing the risk of treatment failure. The reason for the commonly observed low trough concentration of VCM could be related to the relatively low dose of VCM administered due to concerns over its potential for causing renal toxicity. However, increased vascular permeability and temporary kidney injury must also be considered when deciding the VCM dose in patients with severe sepsis as previously described. ${ }^{13}$ The presence of these factors would indicate the need for higher or lower VCM doses. In fact, in this study, multivariate analysis showed that an insufficient total dose of VCM might lead to lower VCM trough concentrations in patients with normal renal function.

Table 3 Multivariate Analysis of Factors Affecting Lower Trough Values of Vancomycin in Patients with eGFR $\geqq 60 \mathrm{~mL} / \mathrm{min}^{\prime} / .73 \mathrm{~m}{ }^{2}$

\begin{tabular}{|l|c|c|c|}
\hline & Adjusted Odds Ratio & $\mathbf{9 5 \%}$ Cl & P value \\
\hline Age & 0.99 & $0.963-1.030$ & 0.75 \\
eGFR $\left(\mathrm{mL} / \mathrm{min} / 1.73 \mathrm{~m}^{2}\right)$ & 0.99 & $0.987-1.010$ & 0.88 \\
CRP $(\mathrm{mg} / \mathrm{dL})$ & 0.938 & $0.886-0.994$ & 0.03 \\
Total dose of VCM $(\mathrm{mg} / \mathrm{kg})$ & 1.07 & $1.020-1.130$ & $<0.02$ \\
\hline
\end{tabular}

Abbreviations: eGFR, estimated glomerular filtration rate; CRP, C-reactive protein; VCM, vancomycin, respectively. 
In Japan, the GL2016 guidelines established an initial target trough VCM concentration range of 15 to $20 \mu \mathrm{g} / \mathrm{mL}$ as a surrogate marker for adequate blood VCM concentrations, although the trough value of 10 to $15 \mu \mathrm{g} / \mathrm{mL}$ is also acceptable. ${ }^{5}$ The reason for this recommendation is that although $10 \mu \mathrm{g} / \mathrm{mL}$ is needed to achieve clinical efficacy, the level needs to remain below $20 \mu \mathrm{g} / \mathrm{mL}$ to prevent the occurrence of side effects associated with kidney damage. Therefore, approximately $10-20 \mu \mathrm{g} / \mathrm{mL}$ has been determined to be the preferred safe and efficient trough value of VCM. ${ }^{5,6}$ We previously reported that mean measured VCM trough values in the patients treated according to established guidelines were generally lower compared with the patients treated not according to established guidelines. ${ }^{11}$ In other words, although using the GL2016 nomogram is associated with enhanced safety, it might reduce clinical efficacy. In order to correct this issue, the GL2016 added an amendment that recommended an initial loading dose of VCM that is slightly higher than that typically given on the first day, in order to enhance clinical efficacy on day $1 .^{5}$ It was also reported that a loading dose of VCM should be considered in all patients with septic shock because the total clearance of VCM was increased in septic shock patients; however, the volume of the central compartment and peripheral compartment did not increase. $^{13}$

According to the CKD guidelines 2012, CKD is defined as disorder of the kidney, as indicated by the presence of proteinuria or an eGFR that is persistently $<60 \mathrm{~mL} / \mathrm{min} / 1.73 \mathrm{~m}^{2}$ for three or more months; this definition has previously been used for the analysis of renal function. ${ }^{12}$ In our previous study, when patients with different severities of renal dysfunction were compared, groups with low renal function had trough VCM levels within the range of adequate blood concentrations when we performed the nomogram-guided monitoring recommended by the GL2016. ${ }^{11}$ Masuda et al retrospectively calculated the eGFR of patients after establishing the initial VCM dose using the computer software for calculation of VCM trough concentration evaluated the efficacy and safety of the dosage recommended by the nomogram, and suggested that an eGFR of between 30 and $80 \mathrm{~mL} / \mathrm{min} / 1.73 \mathrm{~m}^{2}$ might prevent achievement of an adequate blood concentration of VCM. ${ }^{17}$ Suzuki et al retrospectively examined the proportion of patients who achieved the recommended trough levels in the GL2016 group and found that $27.9 \%$ of the subjects in the TDM implementation group achieved a trough level ranging between 10 and $15 \mu \mathrm{g} / \mathrm{mL}$, although $11.6 \%$ of the subjects had trough levels that exceeded $20 \mu \mathrm{g} / \mathrm{mL}$, similar to the results of our previous study $(31 \%) .{ }^{11,18}$ The reasons for these variable results might be due to differences in the patients' background characteristics, including age and inflammation status, as is reflected by ARC, which might frequently lead to the underestimation of renal function and the VCM doses that should be given. Therefore, AUC-guided monitoring is usually recommended over trough-guided monitoring, although both VCM trough concentrations and AUC values correlate with its efficacy and safety. ${ }^{19}$ For AUC-guided monitoring, not only trough levels but also peak VCM concentrations need to be assessed in the patients, especially in septic patients with renal dysfunction, according to the recent TDM recommended by VCM guidelines. ${ }^{7}$

We found total dose of VCM $(\mathrm{mg} / \mathrm{kg})$ was the key factor of the VCM concentration. It was also reported that total daily dose of VCM for trough-based dosing $(2390.76 \pm 1224.59 \mathrm{mg})$ differed significantly from AUCbased dosing (1985.07 $\pm 616.18 \mathrm{mg}$ ) across the cohort, and these differences were dependent on patients' BMI, although not the short status, but the obese patients showed significant differences of total dose of $\mathrm{VCM}^{20}$ These data suggested similar results with our study that the short status looked a significant factor; however, it did not show the significant relation with VCM trough finally. The hematological patients were also not usually obese and did not show high inflammation. Total dose of VCM might be important to increase clinical efficiency and to decrease the risk in TDM, especially in critically ill patients who showed the higher CRP.

\section{Conclusion}

We found that elevated CRP levels might be a risk factor for lower VCM concentration irrespective of the status of renal function. Patients with severe illness might be given lower VCM doses due to the concern of diminished renal function, although such patients are likely to be able to tolerate a higher VCM dose. Hence, higher VCM doses should be considered in patients with severe inflammation, including septic patients, even if they are elderly and short statured, especially when the patients have normal renal function. AUC-guided monitoring, based on both peak and trough concentrations of VCM, should be performed rather than trough-based monitoring. 


\section{Disclosure}

The authors report no conflicts of interest in this work.

\section{References}

1. Song JH, Hsueh PR, Chung DR, et al. Spread of methicillin-resistant Staphylococcus aureus between the community and the hospitals in Asian countries: an ANSORP study. $J$ Antimicrob Chemother. 2011;66:1061-9.9.

2. Yanagihara K, Matsumoto T, Aoki N, et al. Nationwide surveillance of bacterial respiratory pathogens conducted by the surveillance committee of Japanese society of chemotherapy, the Japanese association for infectious diseases, and the Japanese society for clinical microbiology in 2014: general view of the pathogens' antibacterial susceptibility. $J$ Infect Chemother. 2019;25:657-668.

3. Isobe $M$, Uejima $E$, Seki $M$, et al. $J$ methicillin-resistant Staphylococcus aureus bacteremia at a university hospital in Japan. Infect Chemother. 2012;18:841-848. doi:10.1007/s10156-012-0423-6

4. Seki M, Yabuno K, Miyawaki K, Miwa Y, Tomono K. Loading regimen required to rapidly achieve therapeutic trough plasma concentration of teicoplanin and evaluation of clinical features. Clin Pharmacol. 2012;4:71-75.

5. Matsumoto K, Takesue Y, Ohmagari N, et al. Revised practice guidelines for therapeutic drug monitoring of vancomycin: a consensus review of the Japanese society of chemotherapy and the Japanese society of therapeutic drug monitoring. Jpn J Chemother. 2016;1:1-120.

6. Matsumoto K, Takesue Y, Ohmagari N, et al. Practice guidelines for therapeutic drug monitoring of vancomycin: a consensus review of the Japanese society of chemotherapy and the Japanese society of therapeutic drug monitoring. J Infect Chemother. 2013;19:365-380. doi:10.1007/s10156-013-0599-4

7. Rybak MJ, Le J, Lodise TP, et al. Therapeutic monitoring of vancomycin for serious methicillin-resistant Staphylococcus aureus infections: a revised consensus guideline and review by the American Society of Health-system Pharmacists, the Infectious Diseases Society of America, the Pediatric Infectious Diseases Society, and the Society of Infectious Diseases Pharmacists. Am J Health Syst Pharm. 2020;77:835-864.

8. Moise-Broder PA, Forrest A, Birmingham MC, Schentag JJ. Pharmacodynamics of vancomycin and other antimicrobials in patients with Staphylococcus aureus lower respiratory tract infections. Clin Pharmacokinet. 2004;43:925-942. doi:10.2165/00003088-2004 43130-00005

9. Liu C, Bayer A, Cosgrove SE, et al. Clinical practice guidelines by the Infectious Diseases Society of America for the treatment of methicillin-resistant Staphylococcus aureus infections in adults and children: executive summary. Clin Infect Dis. 2011;52:285-292. doi:10.1093/cid/cir034
10. Issaranggoon NA, Ayuthaya S, Katip W, Oberdorfer P, Lucksiri A. Correlation of the vancomycin 24-h area under the concentration-time curve (AUC 24) and trough serum concentration in children with severe infection: a clinical pharmacokinetic study. Int J Infect Dis. 2020;92:151-159. doi:10.1016/j.ijid.2019.12.036

11. Kamioka Y, Suzuki H, Seki M, et al. After Deriving the Initial Dose Setting of Vancomycin with a conventional computer software and a nomogram based on the revised Japanese 2016 therapeutic drug monitoring guidelines for antimicrobial agents. Pharmacol Pharm. 2018;9:88488. doi:10.4236/pp.2018.911037

12. Japanese Society of Nephrology. Clinical practice guidebook for diagnosis and treatment of chronic kidney disease. Jpn J Nephrol. 2012;54:1031-1191.

13. Katip W, Jaruratanasirikul S, Pattharachayakul S, Wongpoowarak W, Jitsurong A, Lucksiri A. The pharmacokinetics of vancomycin during the initial loading dose in patients with septic shock. Infect Drug Resist. 2016;22:253-260. doi:10.2147/IDR.S121513

14. Cook AM, Hatton-Kolpek J. Augmented renal clearance. Pharmacotherapy. 2019;39:346-354. doi:10.1002/phar.2231

15. Shimamoto Y, Fukuda T, Tanaka K, Komori K, Sadamitsu D. Systemic inflammatory response syndrome criteria and vancomycin dose requirement in patients with sepsis. Intensive Care Med. 2013;39:1247-1252. doi:10.1007/s00134-013-2909-9

16. Singer M, Deutschman CS, Seymour CW, et al. The third international consensus definitions for sepsis and septic shock (sepsis-3). JAMA. 2016;315:801-810. doi:10.1001/jama.2016.0287

17. Masuda N, Maiguma T, Komoto A, Haruki Y, Sugiyama T, Teshima D. Validation of vancomycin nomogram using eGFR to calculate initial dosages as stated in the TDM guideline for antibiotics 2016: study in patients with mild to moderate renal dysfunction. Jpn $J$ Ther Drug Monit. 2017;34:132-136.

18. Suzuki A, Tawada H, Namiki M, Ikeda H, Kogo M, Sasaki T. Impact of trough concentration for vancomycin therapy with initial dosage. Jpn J Environ Infect. 2017;32:250-257. doi:10.4058/jsei.32.250

19. Tsutsuura M, Moriyama H, Kojima N, et al. The monitoring of vancomycin: a systematic review and meta-analyses of area under the concentration-time curve-guided dosing and trough-guided dosing. BMC Infect Dis. 2021;21:153. doi:10.1186/s12879-02105858-6

20. Covvey JR, Erickson O, Fiumara D, et al. Comparison of vancomycin area-under-the-curve dosing versus trough target-based dosing in obese and nonobese patients with methicillin-resistant Staphylococcus aureus Bacteremia. Ann Pharmacother. 2020;54:644-651. doi:10.1177/1060028019897100
Infection and Drug Resistance

\section{Publish your work in this journal}

Infection and Drug Resistance is an international, peer-reviewed openaccess journal that focuses on the optimal treatment of infection (bacterial, fungal and viral) and the development and institution of preventive strategies to minimize the development and spread of resistance. The journal is specifically concerned with the epidemiology of antibiotic resistance and the mechanisms of resistance development and diffusion in both hospitals and the community. The manuscript management system is completely online and includes a very quick and fair peerreview system, which is all easy to use. Visit http://www.dovepress.com/ testimonials.php to read real quotes from published authors. 